\title{
Management of Severe and Complicated Malaria in Adults in the Emergency Department of the Regional Hospital of Maradi (Niger)
}

\author{
Kadri Sani ${ }^{1 *}$, Garba Abdoul Azize ${ }^{3}$, Harouna A. M. Laouali ${ }^{2}$, Nahiou Oumarou Saratou ${ }^{1}$, ADA Mahamane Laminou ${ }^{1}$ \\ Daou Mamane ${ }^{4}$, Brah Souleymane ${ }^{4}$ \\ ${ }^{1}$ Department of Internal Medicine/ Hospital Regional Centre of Niamey (Niger) \\ ${ }^{2}$ Department of Internal Medicine/Hospital Regional Centre/Faculty of Health Science, UDD Maradi (Niger) \\ ${ }^{3}$ Department of Internal Medicine/ National Hospital of Zinder/ Faculty of Health Science, UZ Zinder (Niger) \\ ${ }^{4}$ Department of Internal Medicine, Faculty of Health Science, University Abdou Moumouni, Niamey (Niger)
}

\section{Article History \\ Received: 04.12.2021 \\ Accepted: 10.01 .2022 \\ Published: 17.01.2022 \\ Journal homepage: https://www.easpublisher.com}

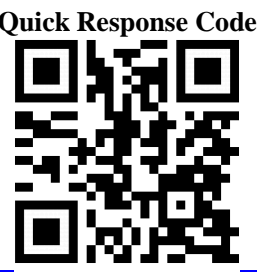

\begin{abstract}
Introduction: In sub-Saharan Africa malaria is the 1st cause of consultation and hospitalization and the 2 nd cause of death in health centres. Maradi region is one of the most malaria-endemic areas with periods of high prevalence, particularly during the rainy season, due to the heavy rainfall that occurs between May and October. Methods: This is a descriptive cross-sectional study conducted in the emergency department of the Regional Hospital Centre of Maradi from August 1st to August 31st, 2017. Results: 104 patients were admitted to the adult emergency department for severe malaria out of 305 admissions to the centre, i.e., a prevalence of $34.1 \%$. Our sample was composed of $53.84 \%$ men $(n=56)$. The average age of our patients was 38.6 years with extremes ranging from 15 to 90 years. Most of the patients had no comorbidity ( $80.76 \%$ of cases). Thick blood drop was used for diagnosis in $93.25 \%$ of cases $(n=97)$. The main clinical manifestations were: neurological forms $(34,61 \% \mathrm{n}=36)$, severe anemia $(31,73 \% \mathrm{n}=33)$. Conclusion: This study shows that malaria is a major public health problem in subSaharan Africa and particularly in Niger because of its prevalence, severity and morbidity.
\end{abstract}

Keywords: Management, severe malaria, adults, emergency department, Maradi, Niger.

Copyright (C) 2022 The Author(s): This is an open-access article distributed under the terms of the Creative Commons Attribution 4.0 International License (CC BY-NC 4.0) which permits unrestricted use, distribution, and reproduction in any medium for non-commercial use provided the original author and source are credited.

\section{INTRODUCTION}

Malaria remains the largest parasitic endemic worldwide, nearly half of the world's population was at risk of malaria in 2015 in 91 countries, which there were 212 million malaria cases and 429,000 deaths [1, 2]. Malaria morbidity and mortality have declined significantly since 2000 but this remains significant in 2015. Most malaria cases and associated deaths are estimated to occur in the WHO African region (88\%). In $2015,90 \%$ of malaria cases and $92 \%$ of deaths occurred in 13 countries in this region $[1,2]$.

However, the percentage of malaria infections among the population at risk in sub-Saharan Africa decreased from $17 \%$ in 2010 to $13 \%$ in 2015 [1-4]. In Niger, malaria remains a major public health problem, in that it is the 1st cause of consultation and hospitalization and the 2nd cause of death in health centres, particularly among children under 5 years of age [3,4]. The region of Maradi is one of the most malaria-endemic areas with periods of high prevalence, particularly during the rainy season, due to the heavy rainfall that occurs between May and October [6].

The Emergency Department (EC) acts as a primary access point for entry into the healthcare system [5]. The problem of management and the lack of previous studies in the emergency department of the Maradi Regional Hospital on this issue motivated the choice of this topic.

The objective of this study is to determine the epidemiological, clinical and therapeutic aspects of severe malaria in adult in the emergency department of the Regional Hospital Centre (CHR) of Maradi.

\section{Methods ANd Materials Study Design}

This is a descriptive cross-sectional study conducted in the emergency department of the Regional

*Corresponding Author: Kadri Sani

Department of Internal Medicine/ Hospital Regional Centre of Niamey (Niger) 
Hospital Centre of Maradi from August 1st to August 31st, 2017.

The study was conducted at the Maradi Regional Hospital. This hospital is a regional referral Centre, that it receives patients from other centres that do not have sufficient technical facilities or the necessary skills. The emergency department which was the subject of our study includes a triage and referral unit for adults and children, an emergency hospitalization unit and shock unit.

The study population consisted of adult subjects of both sexes over 15 years of age admitted for severe malaria confirmed according to the severity criteria defined by WHO.

Severe malaria is defined in any patient with at least one World Health Organization (WHO) severity criteria associated with a positive thick drop and/or a positive rapid diagnostic test (RDT) sensitive to Plasmodium falciparum regardless of parasite density.

The antimalarial drugs used were parenteral artemether at $3.2 \mathrm{mg} / \mathrm{kg}$ intramuscular (IM) the first day, then $1.6 \mathrm{mg} / \mathrm{kg}$ from day 2 to 5 , parenteral artesunate at $2.4 \mathrm{mg} / \mathrm{kg}$ intravenous (IV) at $\mathrm{H} 0, \mathrm{H} 12$, $\mathrm{H} 24$, day 2 to 5 with oral relay as long as the patient's clinical condition improved followed by 3 days of artemisinin-based combination therapy (ACT) (World Health Organization, 2015), and quinine at a dose of $24 \mathrm{mg} / \mathrm{kg} / 24$ hours [4-7].

The other therapeutic means were transfusion of red blood cells at a dosage of $20 \mathrm{ml} / \mathrm{kg}$, antibiotic therapy, hydro-electrolytic support and nursing care.

We included in our study all patients of both sexes hospitalized for severe malaria with a positive thick blood drop and/or a positive rapid diagnostic test (RDT) sensitive to Plasmodium falciparum and who met the WHO criteria for severity of malaria.

All patients with a condition other than malaria that may have caused the clinical symptomatology and/or death were not included in our study.

The following variables were studied: age, sex, origin, existence of comorbidity, clinical manifestation of severity and treatment administered

\section{Data Collection and Statical analysis}

Data collection was done with strict respect for anonymity after an informed consent. The data were collected on a form designed for the purpose of the study.

Data analysis was performed with the software: Epi info, version 3.6. We calculated proportions with $95 \%$ confidence intervals (CIs). Data entry and presentation of figures with Microsoft Excel and Word 2013.

\section{RESULTS}

During this study period, 104 patients were admitted to the adult emergency department for severe malaria out of 305 admissions to the centre, i.e., a prevalence of $34.1 \%$.

Our sample was composed of $53.84 \%$ men $(n=56)$ and $46.16 \%$ women $(n=48)$, a sex ratio of 1.16 in favor of men. The average age of our patients was 38.6 years with extremes ranging from 15 to 90 years?

The age range 16-25 years was the majority $(38.46 \% \mathrm{n}=40)$ followed by the age range $26-50$ years in $34.61 \%$ of cases $(n=36)$, the age range $51-65$ years in $15.38 \%(n=16)$. The age group over 65 years was represented in $11.53 \%$ of cases $(n=12)$.

The majority of our patients came from the city of Maradi $(58.65 \% \mathrm{n}=61)$ while $41,34 \% \quad(\mathrm{n}=43)$ come from others health centres according to the referral and counter-referral system.

Most of the patients had no comorbidity ( $80.76 \%$ of cases); hypertension and diabetes were found in $13,46 \%(n=14)$ and $5,76 \%(n=6)$ of patients respectively. In terms of biology, all patients had a thick drop for the diagnosis of malaria, a CBC, venous glycemia, urea and creatinine.

Thick blood drop was used for diagnosis in $93.25 \%$ of cases $(n=97)$ and rapid diagnostic test (RDT) in $6.73 \%$ of cases $(n=7)$.

The manifestations of severe malaria (fig. 1) were: neurological forms $(34,61 \% \mathrm{n}=36)$, severe anemia: $\mathrm{Hb}<5 \mathrm{~g} / \mathrm{dl}(31,73 \% \mathrm{n}=33)$, hypoglycemia $(6,73 \% \mathrm{n}=7)$, acute respiratory distress syndrome $(7,69 \% \mathrm{n}=8)$, Acute renal failure $(5,76 \% \mathrm{n}=6)$, shock and cardio-vascular collapse $(6,73 \% \mathrm{n}=7)$, and jaundice $(3,84 \% \mathrm{n}=4)$, mixed forms that combine several signs of severity $(2.88 \% \mathrm{n}=3)$.

Treatment consisted of the administration of artemether $(67,30 \%, \mathrm{n}=70)$, artesunate injection $(24,03 \%, \mathrm{n}=25)$ and quinine $(8.65 \%, \mathrm{n}=9)$ combined with antibiotic therapy $(70.19 \%)$ and blood transfusion $28 / 33$ patients with severe anemia such as $26,92 \%$ of all patients.

The evolution of patient after treatment is characterized by death rate $(22.11 \% \mathrm{n}=23)$, the recovery of patients $29,80 \%$ and transfer to other departments $48,07 \%$. 
Table-I: Distribution of patients according to characteristics: epidemiological, clinical and therapeutical

\begin{tabular}{|c|c|c|c|c|}
\hline \multirow{3}{*}{$\begin{array}{l}\text { Parameters } \\
\text { Gender }\end{array}$} & \multirow{2}{*}{$\begin{array}{l}\text { Classification } \\
\text { Male }\end{array}$} & Number & \multicolumn{2}{|c|}{ Frequency } \\
\hline & & \begin{tabular}{l|l} 
& 56 \\
\end{tabular} & & $53.84 \%$ \\
\hline & Female & 48 & & 46,16 \\
\hline \multirow{4}{*}{ Age, yr } & $16-25$ & 40 & $38.46 \%$ & \\
\hline & $26-50$ & 36 & $34.61 \%$ & \\
\hline & $51-65$ & 16 & $15.38 \%$ & \\
\hline & $>65$ & 12 & $11.53 \%$ & \\
\hline \multirow[t]{3}{*}{ Provenance } & Rural & 43 & $41.34 \%$ & \\
\hline & Urban & 61 & $58.65 \%$ & \\
\hline & Unschooled & 48 & $46,15 \%$ & \\
\hline \multirow[t]{3}{*}{ Education } & Primary school & 29 & $27,88 \%$ & \\
\hline & Secondary School & 16 & $15,38 \%$ & \\
\hline & Graduate or Higher & 11 & $10,57 \%$ & \\
\hline \multirow{3}{*}{$\begin{array}{l}\text { Medical } \\
\text { history }\end{array}$} & No One & 84 & $80.76 \%$ & \\
\hline & Hypertension & 14 & $13.46 \%$ & \\
\hline & Diabetes & 6 & $5.65 \%$ & \\
\hline \multirow[t]{2}{*}{ Diagnosis } & Thick blood drop & 97 & $93.25 \%$ & \\
\hline & RTD & 7 & $6.75 \%$ & \\
\hline \multirow{3}{*}{ Treatment } & Artesunate & 25 & $24,03 \%$ & \\
\hline & Artemether & 70 & $67,30 \%$ & \\
\hline & Quinine & 9 & $8,65 \%$ & \\
\hline \multirow[t]{2}{*}{ Antibiotics } & Yes & 73 & $70,19 \%$ & \\
\hline & No & 31 & $29,80 \%$ & \\
\hline \multirow{2}{*}{$\begin{array}{l}\text { Blood } \\
\text { Transfusion }\end{array}$} & Yes & 28 & $26,92 \%$ & \\
\hline & No & 76 & $73,07 \%$ & \\
\hline \multirow[t]{3}{*}{ Evolution } & Recovery & 31 & $29,80 \%$ & \\
\hline & Transfer & 50 & $48,07 \%$ & \\
\hline & Death & 23 & $22,11 \%$ & \\
\hline
\end{tabular}

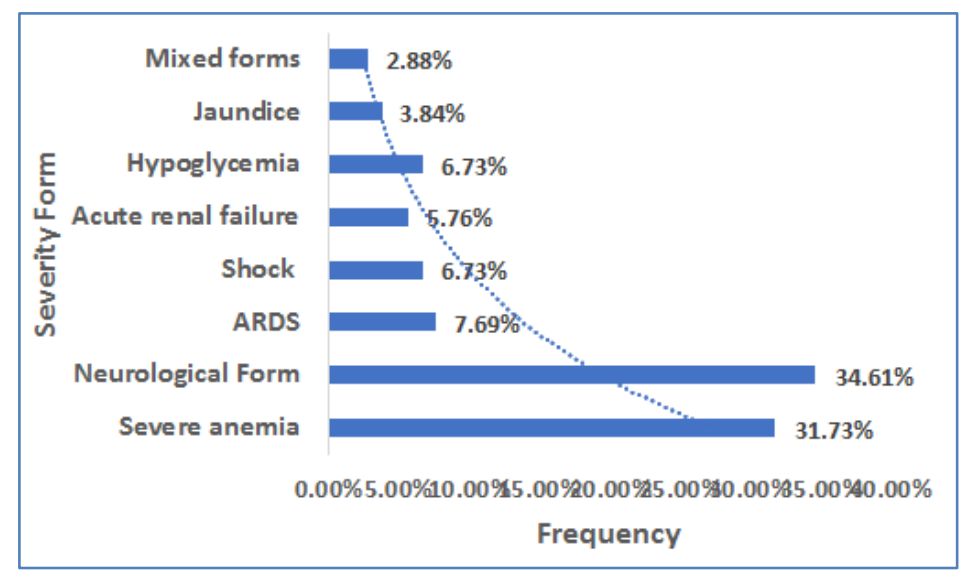

Fig-1: Distribution of patients according to severity form of malaria

\section{DiscuSSION}

The findings of this study revealed that management of severe malaria in emergency department in Niger remains one of the priorities because of its prevalence, severity and morbidity. Our work shows several epidemiological and clinical challenges during severe malaria in adults in an emergency department during the peak period. This study shows that the morbidity of severe adult malaria in Niger during the peak period remains high $(34.1 \%)$. This situation is comparable to that reported by other studies in sub-Saharan Africa and India [6-11].
The choice of the period of this study confirms the persistence of high frequencies during the raining period compared to the so-called dry period of the year during which the hatching of parasites and larval sites remain less as reported by $\mathrm{S}$. Kadri et al. in Maradi (Niger) [6].

We observed a difference between the origin of the patients and the occurrence of severe malaria with a slight predominance of children from the city of Maradi, this could be explained by the proximity of the hospital to this population. Patients coming from other centres are complicated cases that have encountered 
difficulties in management. This is illustrated by several African studies [6-11]. Diabetes and hypertension remain the most associated comorbidities in the occurrence of severe and complicated malaria in emergency departments. Neurological and anemic complications are the main forms of malaria severity encountered. This has been reported by several African authors [6-10].

The treatment is based on parenteral artesunate, artemether or quinine. This is in accordance with the new guidelines of the national malaria control program and the WHO which recommends the administration of the parenteral artemisinin drug, artesunate, is a first-line treatment for severe Plasmodium falciparum infection worldwide [10-13].

\section{CONCLUSION}

This study shows that severe malaria in adults is a major concern in clinical practice in the emergency department, particularly in high frequency areas. Anemic, neurological complications constitute the main clinical presentations of severe and complicated malaria in the emergency department.

\section{REFERENCES}

1. WHO. (2016). World Malaria Report http://www.who.int

2. Pierre Aubry, Bernard-Alex Gaüzère. (2016). Paludisme, Actualités, Med. Trop www.medecinetropicale.com

3. INS Institut National de la Statistique. (2015). Annuaire Statistique Régional de Maradi 2010 2014, édition

4. Anon. (2012). World Health Organization; Management of Severe Malaria - A Practical Handbook, 3rd ed. http://www.who.int.

5. Ngaruiya, C., Kawira, A., Mali, F., Kambua, F., Mwangi, B., Wambua, M., ... \& Wachira, B.
(2021). Systematic review on epidemiology, interventions and management of noncommunicable diseases in acute and emergency care settings in Kenya. African Journal of Emergency Medicine, 11(2), 264-276.

6. S Kadri, A.M.L., Harouna, C., Salaou, M., Daou, A.M., Neino, M., Ahmadou, B. (2020) Children's severe malaria in the Regional Hospital Center of Maradi (Niger). Jaccr Africa; 4(4); 51-55 www.jaccrafrica.com

7. Gai. (2018). Manifestation of malaria in Mangaluru, southern India, Malar J, 17; 313 https://doi.org/10.1186/s12936-018-2462-7.

8. Yusuph, R., Sawe, H. R., Nkondora, P. N., \& Mfinanga, J. A. (2019). Profile and outcomes of patients with acute complications of malaria presenting to an urban emergency department of a tertiary hospital in Tanzania. BMC research notes, 12(1), 1-5.

9. Idro, R., \& Aloyo, J. (2004). Manifestations, quality of emergency care and outcome of severe malaria in Mulago Hospital, Uganda. African health sciences, 4(1), 50-57.

10. Kefyalew, T., Kebede, Z., Getachew, D., Mukanga, D., Awano, T., Tekalegne, A., ... \& Hamade, P. (2016). Health worker and policy-maker perspectives on use of intramuscular artesunate for pre-referral and definitive treatment of severe malaria at health posts in Ethiopia. Malaria journal, 15(1), 1-10.

11. Elnour, F. A., Alagib, M. E., Bansal, D., Abd Farag, E. A. B., \& Malik, E. M. (2019). Severe malaria management: current situation, challenges and lessons learned from Gezira State, Sudan. Malaria journal, 18(1), 1-8.

12. Varo, R., Crowley, V. M., Sitoe, A., Madrid, L., Serghides, L., Kain, K. C., \& Bassat, Q. (2018). Adjunctive therapy for severe malaria: a review and critical appraisal. Malaria journal, 17(1), 1-18.

Cite This Article: Kadri Sani, Garba Abdoul Azize, Harouna A. M. Laouali, Nahiou Oumarou Saratou, ADA Mahamane Laminou, Daou Mamane, Brah Souleymane (2022). Management of Severe and Complicated Malaria in Adults in the Emergency Department of the Regional Hospital of Maradi (Niger). East African Scholars J Med Sci, 5(1), 10-13. 